\title{
Малхар Кулкарни \\ Взаимодополняющее развитие языкознания и философии языка в Индии
}

\begin{abstract}
Аннотация: в статье показано взаимодействие языкознания и философии языка в истории Индии и в процессе создания новейших технологий машинного перевода текстов. Для этой страны характерны многообразие языков и стремительное развитие технологий, применяемых в сфере языкознания, особенно для нужд образования. Автор прослеживает влияние лингво-философской традиции, в особенности идей известного грамматиста Панини (V-IV вв. до н. э.), на современные разработки. Освещены наиболее значительные концепции Панини. Затронуты основные темы философских дискуссий, отражающих развитие науки о языке.

Ключевъе слова: культурология, языкознание, философия, индийская культура, лингвистическое разнообразие, стандартизация, грамматический формализм Панини, метаязык, когнитивные аспекты языка.
\end{abstract}

B Индии с древности языкознание и философия языка развивались в тесном взаимодействии. Грамматика (вьякарана) оформилась в самостоятельную науку, когда величайшим грамматистом древности Панини (V-IV вв. до н. э.) было написано его знаменитое «Восьмикнижие» («Аштадхьяи»)1. В этой книге мы найдем не только первое систематическое описание древнеиндийского литературного языка (санскрита), но и основания для философских дискуссий. Творческое взаимодействие философии и науки о языке продолжается в Индии по сей день. Его характер и тенденции определяются ситуацией чрезвычайного многообразия языков, на которых говорят индийские этносы и народности. Сегодня в стране только официальных языков насчитывается $23^{2}$. Они относятся к четырем языковым семьям: индоарийской, дравидийской, тибето-бирманской и австроазиатской (аустроазийской), приходившим на территорию субконтинента в разные периоды истории и закрепившимся там. Помимо официальных, существуют еще более 1500 диалектов, на которых говорят в разных частях страны ${ }^{3}$. Лингвистические богатство и разнообразие, несомненно, представляют собой уникальную черту индийской культуры. Однако, взглянув на информационные ресурсы (как печатные, так и

\footnotetext{
${ }^{1}$ Это грандиозное сочинение состоит из 4000 предельно лапидарных афоризмов-сутр, каждая из которых включает лишь несколько слогов.

2 Это ассамский, бенгали, бодо, догри, гуджрати, хинди, каннада, кашмири, конкани, майтхили, малаялам, манипури, маратхи, непали, ория, пенджаби, санскрит, сантхали, синдхи, тамил, телугу, урду и английский.

${ }^{3}$ Конгломерация из 800 таких диалектов 6-7 января 2012 г. была организована в г. Вадодаре (бывший г. Барода; Гуджарат, Индия) под эгидой неправительственной организации Вак, расположенной в Вадодаре.
}

электронные), описывающие необъятное множество языков, мы огорчимся тем, что ресурсов так немного, что Индия богата языками, но бедна ресурсами. Ученые-лингвисты при поддержке правительства Индии неоднократно предпринимали и предпринимают попытки исправить ситуацию и создать печатные и электронные ресурсы такого рода, в частности новейшие технологии машинного перевода с одного индийского языка на другой индийский язык ${ }^{4}$.

Благодаря их усилиям мы наблюдаем стремительное развитие технологий языкознания в Индии, особенно в образовательной среде. Уже определились лидеры в этом процессе - образовательные учреждения, расположенные в различных регионах страны и заинтересованные в развитии ресурсов на соответствующих языках. При развитии технологий языкознания их разработчики сталкиваются с различными типами проблем. Первой в их ряду можно назвать проблему стандартизации средств перевода. Стандартизация процесса очень важна для развития технологий, а договориться и принять что-либо в качестве стандарта в такой огромной и многообразной стране, как Индия, чрезвычайно сложно.

В процессе разработки лингвистических технологий: используется наличный лингвистический ресурс (под ним мы подразумеваем местный языковой ресурс, точнее - любую лингвистическую теорию, грамотно объясняющую языковую действительность Индии, словари и грамматики); за-

\footnotetext{
${ }^{4}$ На Западе самым передовыми системами для машинного перевода текстов считаются так называемые И-системы, которые применяются сегодня в наиболее современных электронных переводчиках. Алгоритм, по которому ими осуществляется перевод, предполагает смысловой анализ исходного текста.
} 
Культура и искусство 2(14) • 2013

действуется философское понимание лингвистических феноменов, с которыми приходится иметь дело. И это понимание само по себе является другой важной проблемой, требующей решения. В ее решении неоценимую роль играет применение лингво-философской концепции Панини.

Доказательством этого тезиса служит использование грамматического формализма Панини ${ }^{5}$ при разработке банка деревьев синтаксического анализа (parse tree ${ }^{6}$ banks) для индийских языков. Проекты, связанные с машинным переводом с одного индийского языка на другой индийский язык (МП ИЯ-ИЯ) базируются на идее применимости названного формализма для обработки всех индийских языков. В предлагаемых в их рамках технологиях структура предложения на санскрите, выявленная Панини, берется за образец для установления синтаксической структуры всякого заданного входного предложения на любом индийском языке, а в качестве языка описания употребляются введенные Панини специальные санскритские термины, за которыми в неизменном виде сохраняются их философские коннотации. Например, Панини для объяснения взаимосвязи слов в предложении (в особенности несущих главную смысловую нагрузку - глаголов и существительных), ввел в свою систему категорию карака7. Караки обозначают различные роли, в которых могут выступать существительные применительно к действию. У Панини эти роли таковы: карта (деятель), карман (объект), карана

5 Одной из заслуг Панини считают то, что он впервые в языкознании реализовал системный подход к анализу языка. Суть этого подхода - сведение конкретных языковых фактов к набору исходных элементов, из которых по определенным правилам можно выстроить все множество явлений языка. В числе заслуг великого грамматиста введение в языкознание понятия нулевой формы (нулевого элемента), аналогичной нулю в математике, использование для описания санскрита символического языка выступающего по отношению к описываемому языку как метаязык, приближение к понятию класса лингвистических единиц. Его грамматике неоднократно подражали. Влияние его теории грамматики (в частности, различение метаязыка и языка-объекта, использование символизма для анализа языка, постановка проблемы знака, автономного употребления слов и др.) на развитие лингвистической мысли в мире возрастает, охватывая методологию ряда наук. - Примеч. ред. Подробнее см.: Bharati A., Chaitanya V., Sangal R.A Natural Language Processing: Paninian perspective (Indian Institute of Technology, Kanpur). New Delhi: Prentice-Hall of India. 1995.

${ }^{6}$ Parse tree (дерево синтаксического анализа) - важный термин современной информатики. Построение такого дерева является результатом синтаксического анализа (парсинга), который представляет собой процесс сопоставления линейной последовательности лексем (морфологических единиц) языка с его формальной грамматикой. Формальную грамматику санскрита создал Панини.

7 Караки (в переводе с санскрита: «действующие») - лингвистическая и лингвофилософская категория. - Примеч. ред. (инструмент), сампрадана (реципиент), ападана (точка отправления) и адхикарана (субстрат/ локус). Эти смысловые категории учитываются в технологиях машинного перевода. Правда, в наше время паниниевский список карак был пополнен новой каракой, используемой для обозначения некоторых явлений в теории, а также при компьютерной обработке текстов: анубхава карта (Experiencer Agent - воспринимающий агент).

Использование формализма Панини уже позволило создать банк деревьев синтаксического анализа для языка бенгали. Банки деревьев для хинди, маратхи, каннада и других языков находятся в процессе создания. В данных разработках приходится учитывать философский аспект рассмотрения языка и понимания его основных ограничений, как это делают, например, разработчики различных лексических инструментов (таких как тезуарусы ${ }^{8}$ ) для индийских языков типа Indo-Wordnet 9 .

Приведенные примеры позволяют нам утверждать, что индийское языкознание в области компьютерной лингвистики развивается и движется вперед рука об руку с философией языка. Это не удивительно, учитывая, что на сцене индийской истории их союз насчитывает уже более 2500 лет и что Индия заслуженно гордится своей великой традицией лингвистической мысли ${ }^{10}$, восходящей еще к тому периоду ${ }^{11}$, когда пророки «Ригведы» слагали гимны во славу языка и задавались вопросами о его природе и форме. Заметными вехами в истории лингво-философской мысли Индии стали также такие тексты, как Падапатха ${ }^{12}$, традиционно приписываемая древнему грамматисту Гаргъе, и этимологическое сочинение «Нирукта» Яски (700 г. до н. э.). Падапатху можно считать первым исследованием «Ригведы», поскольку в этой редакции священного текста ведийские гимны делятся на слова, а значит, устанавливаются и границы слов. «Нирукта» является одним из древнейших текстов

${ }^{8}$ Тезаурус (от греч. thesaurós - сокровище, сокровищница) в одном из значений - множество смысловых единиц некоторого языка (естественного, специального языка какойлибо науки или языка программирования) с заданной на нем системой семантических отношений. - Примеч. ред.

9 Indo-Wordnet - это обширная «зонтичная» структура, в рамках которой различные индийские институты разрабатывают свои тезаурусы. Индийский Технологический институт в Бомбее взял на себя составление трех тезаурусов: для хинди, маратхи и санскрита. Подробнее см. на www. cfilt.iitb.ac.in

${ }^{10}$ Подробнее см.: Belvalkar 1976.

${ }^{11}$ Около середины II тысячелетия до н.э. - Примеч. ред.

12 Эта редакция «Ригведы», название которой можно буквально переводить как «пословный текст», отличается от Самхиты (или Самхитапатхи) тем, что здесь не используются правила сандхи - слияния последней буквы предыдущего слова и первой буквы следующего, приводящего к изменению звучания текста. В Падапатхе слова гимна не сливаются, а в Самхитапатхе - сливаются.- Примеч. ред. 
Знак, слово, речь, язык

по науке этимологии и также содержит принципы, представляющие интерес для современных ученыхлингвистов. Однако ни Падапатха, ни «Нирукта» не могут затмить заслуг Панини, приблизившего науку о языке к теоретическому совершенству созданием формальной грамматики санскрита.

Дальнейшая теоретическая эволюция индийской лингвистики была связана с разработкой теории предложения. Панини использовал термин «вакья» в значении «предложение», хотя и не дал ему определения в своей грамматике. Дефиницию термина «вакья» дал спустя почти два века Катьяяна (30о г. до н. э.), написавший: «ekatin̄ vākyam» (цепочка слов, содержащая один tin̄, называется предложением). В индийской грамматике tin̄- это сово- купность постфиксов ${ }^{13}$ (терминальных суффиксов), присоединяемых к корню глагола. Определение Катьяяны учитывает, таким образом, формальный аспект предложения. Несколькими веками позже другой замечательный грамматист Бхартрихари (около V в. н. э.), размышляя над определением понятия «вакья», предложил 10 дефиниций предложения, учитывающих помимо структуры предложения его значение и выразительный аспект.

Панини стал родоначальником лингвистического анализа, выделив в качестве компонентов предложения словоформы (pada) с их собственной структурой, включающей корень и постфикс. Полученная с помощью такого анализа структура представлена на схеме 1:

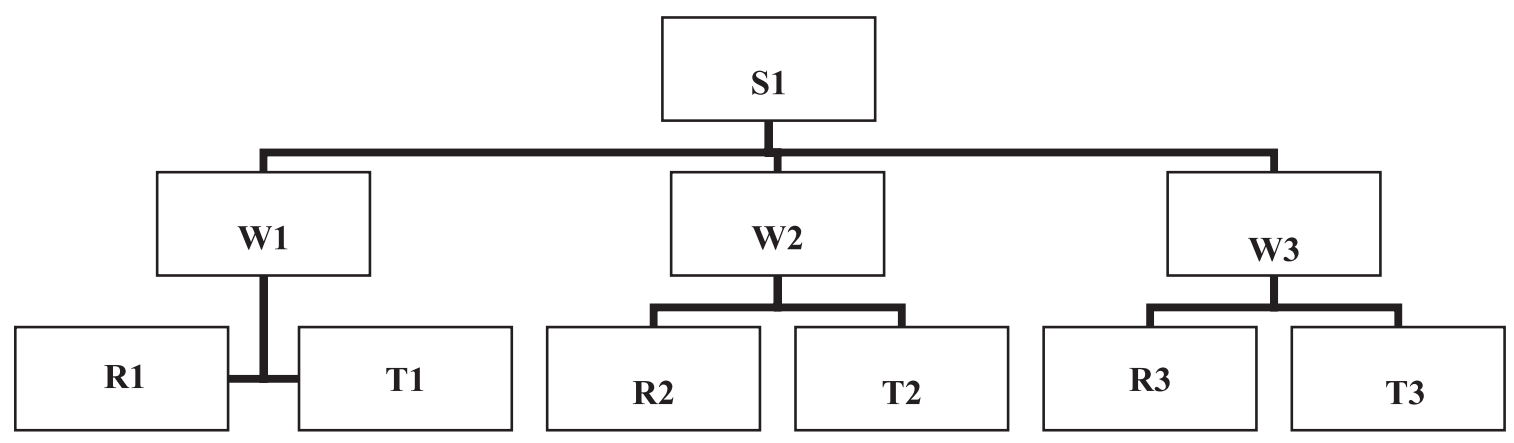

Схема 1. Используемые обозначения: $\mathrm{S}$ - предложение, $\mathrm{W}$ - слово, $\mathrm{R}$ - корень, T - постфикс.

Схему 1 можно пояснить на примере следующего предложения (схема 2, в которой һ обозначает отсутствие постфикса):

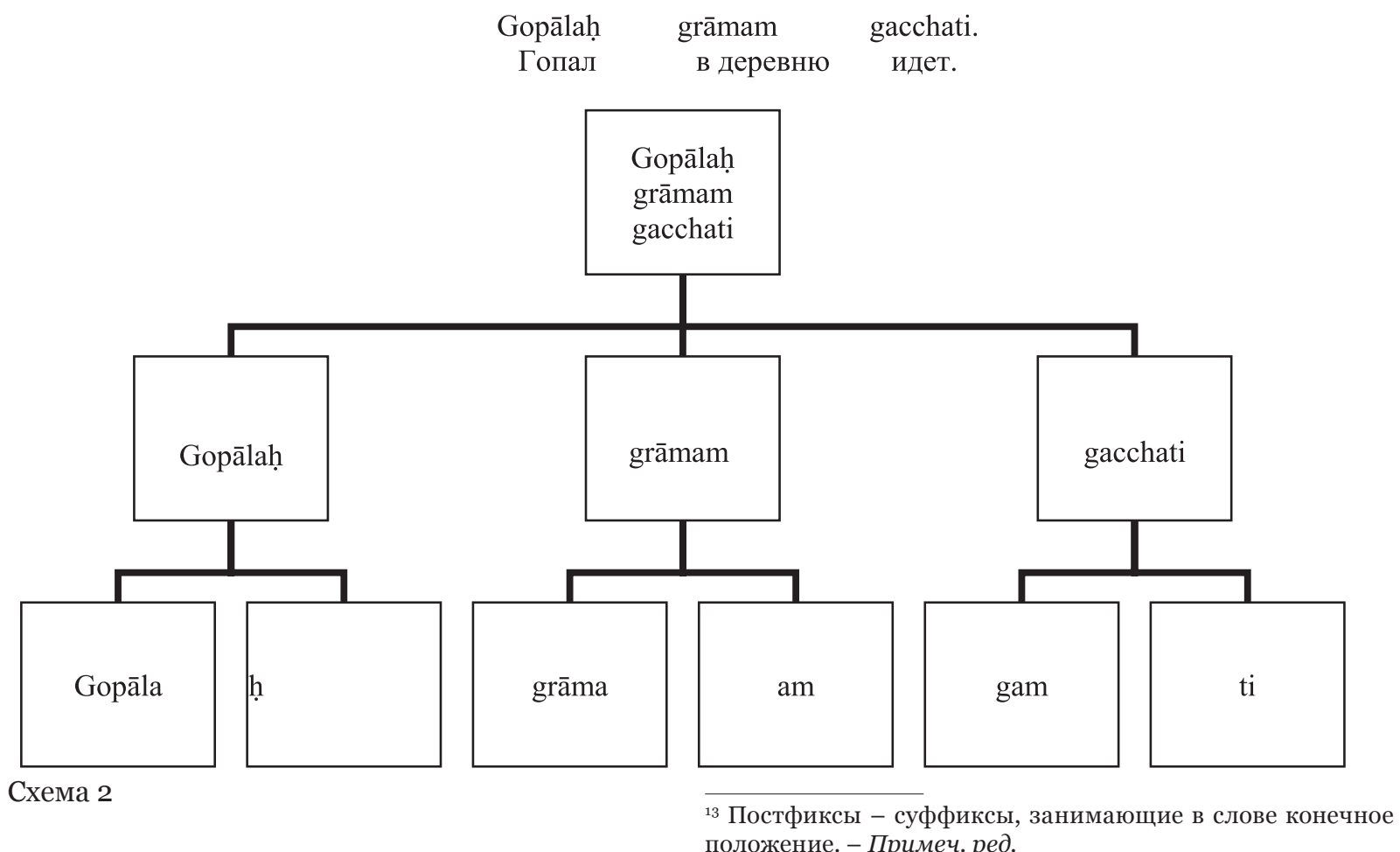
положение. - Примеч. ред. 


\section{Культура и искусство 2(14) • 2013}

Основываясь на схеме 2, можно создать модель семантической структуры предложения (схема 3):

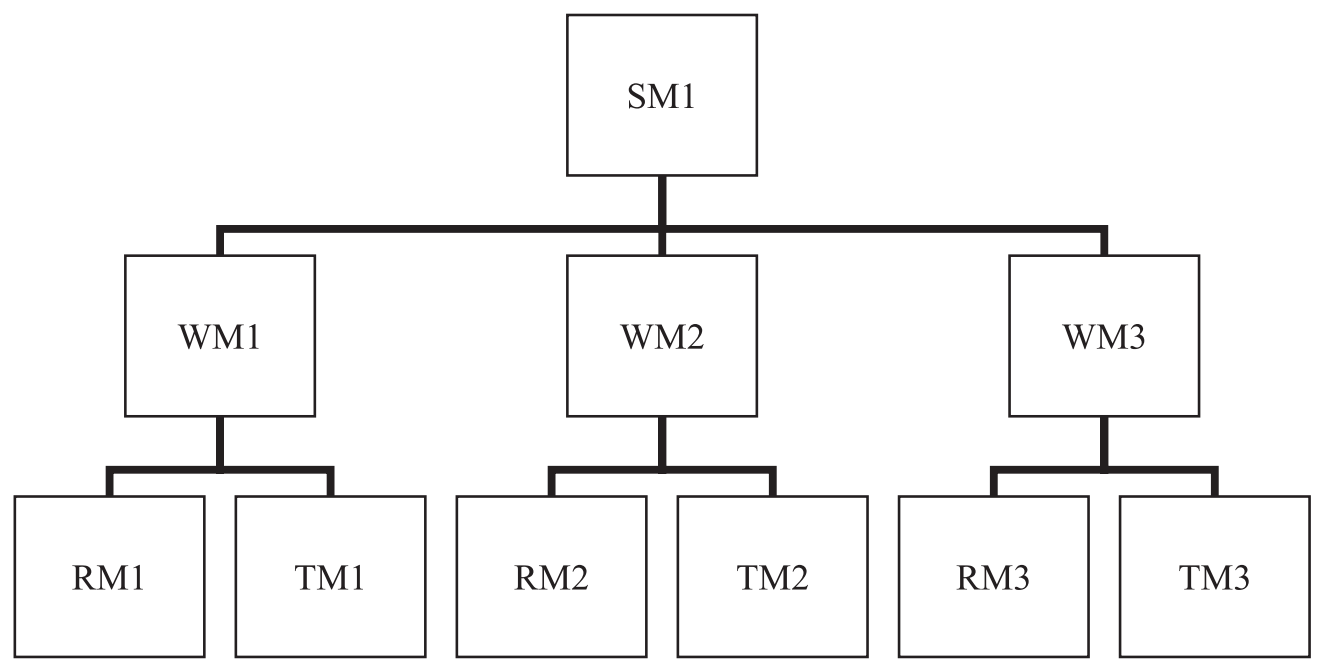

Схема 3. Семантическая структура предложения. Принятые обозначения: SM - значение предложения, WM - значение слова, RM - значение корня, TM - значение окончания.

Применив полученную модель к уже использовавшемуся предложению, получим схему 4:

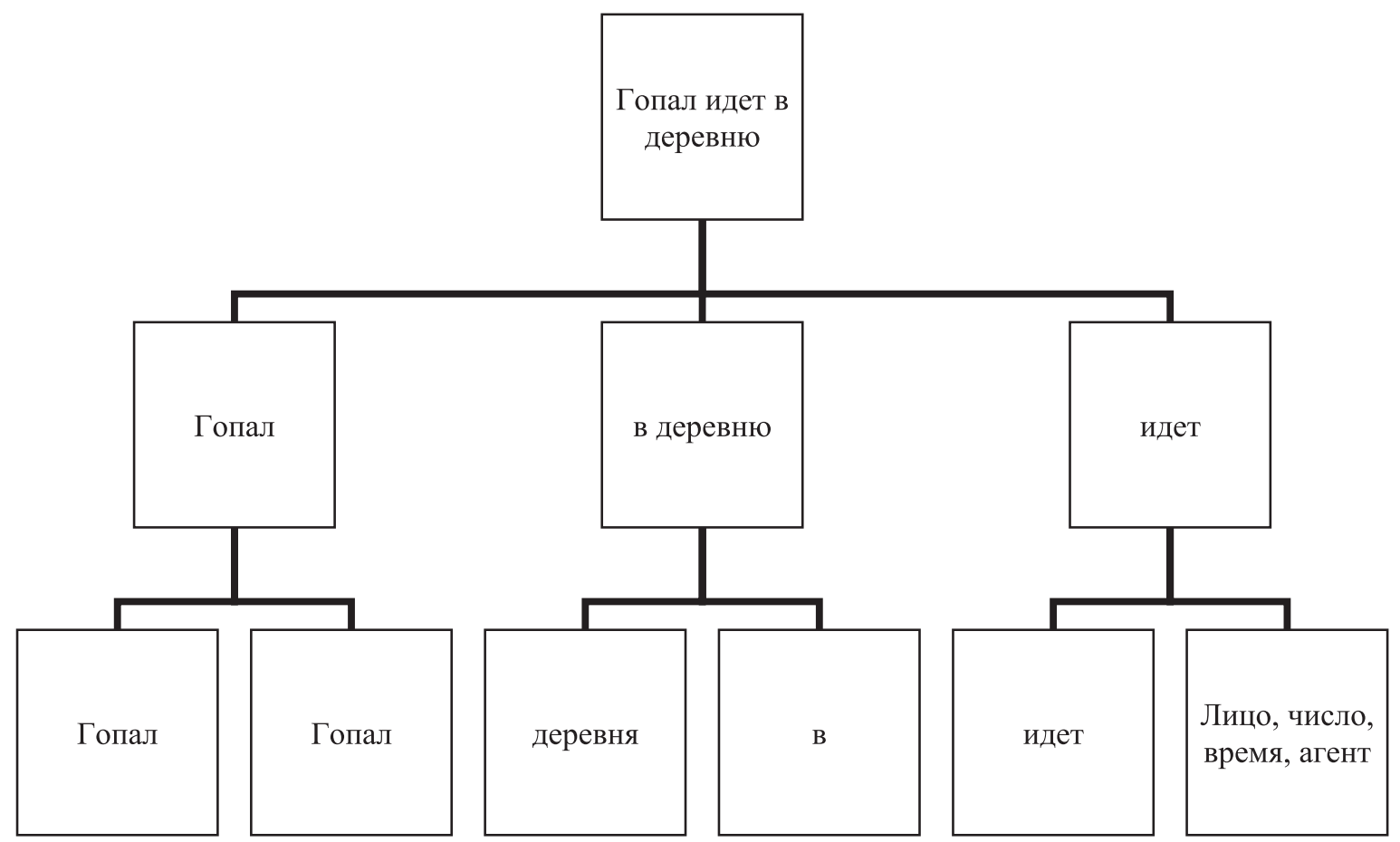

Схема 4. Пример семантической структуры предложения

Подставляя в схему 3 разные слова, можно получить все предложения на санскрите. Однако дерево на схеме 4 - это не дерево синтаксического анализа (parse tree), поскольку названные деревья точно показывают взаимосвязь слов и отражают отношения вершина-модификатор ${ }^{14}$. На приведенных

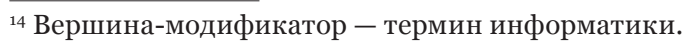

выше схемах изображена внутренняя структура, не зависящая от грамматической теории вершин (head) и т. п.

При создании алгоритмов машинного перевода учитывается формальная грамматика исходного языка, с одной стороны, и того, на который осуществляется перевод, - с другой. Созданная Панини формальная грамматика санскрита, как 
было отмечено выше, принята за образцы формальных грамматик всех остальных индийских языков, именно поэтому понимание идей Панини сегодня так важно. Анализ структуры предложения у него не останавливается на выделении в словах корней и постфиксов ${ }^{15}$. Грамматист разделил на две обширные категории также корни (prātipadika - именные корни, dhātu - глагольные корни) и окончания (sup - именные окончания, tin̄ - глагольные окончания), а корни в свою очередь поделил на простые и производные. Простые глагольные корни перечислены в приложении к его грамматике, как и некоторые простые именные корни. Производные корни образуются по грамматическим правилам. Производные именные корни он также классифицировал по нескольким видам: корни сложных слов (главным образом, четырех типов), отглагольных существительных и др.

Панини, должно быть, много размышлял над отнесением грамматических элементов к каждой из указанных категорий, что привело его к завершению сегментации смысловых единиц и, в конечном счете, к генерации лингвистической системы. Его решение о категоризации корневых морфем, вероятно, было тесно связано с решением определить точную фонологическую форму окончаний. Два означенные решения позволяют решить задачу формулировки грамматических правил, применимых к различному лингвистическому, фонологическому, морфологическому, а также синтаксическому окружению. Панини установил и определенные принципы, при помощи которых противоречия, возникающие между двумя правилами, действующими в различных окружениях, разрешимы таким образом, чтобы дать возможность дойти до заданной формы на уровне поверхностной структуры. Он обозначил ударение мельчайших элементов и вставил его в структуру предложения, показанную выше. Таким образом, ему пришлось снабдить ударением все без исключения грамматические элементы и разработать правила акцентуации, регламентирующие динамику тона в процессе генерации словоформ.

Поскольку санскрит принадлежит к числу морфологически богатых языков, Панини разработал «стратегию замены (Substitution) ${ }^{16}$ » с тем, чтобы объяснить взаимосвязь форм поверхностного уровня и базовых грамматических элементов. Он установил для случаев замены принцип «распространения свойств» от «заменяемого» на «заменяющее», и обратно. Грамматист прописал также

${ }^{15}$ Подробнее см.: Cardona G. Pāninini: a survey of research. Delhi: Motilal Benarsidass, 1976; Cardona G. Recent Researches in Pānininian studies. Delhi: Motilal Benarsidass, 1998.

${ }^{16}$ Субституция - замена частей слова при словообразовании. - Примеч. ред. последовательность применения правил в процессе образования словоформ в зависимости от окружения: в первую очередь применяются синтаксические правила, затем - морфологические, после них - фонологические. После применения фонологических правил применение морфологических правил уже невозможно. Располагая таким арсеналом теоретических средств, Панини смог объяснить множество лингвистических явлений. А те, что не укладывались в его теоретические схемы, он объяснил с помощью правил, выделенных в особый раздел его грамматики, «как бы не существующий» для всех прочих правил. Этот раздел в основном состоит из правил, регулирующих фонологические изменения, которые применяются в последнюю очередь.

На приводившихся выше схемах 1-4 связь между словами, составляющими предложение, четко не выражена. В санскритской традиции эта связь дискутировалась, на ее счет сложились разные точки зрения. Грамматисты - последователи Панини неукоснительно утверждают, что данная взаимосвязь есть не что иное, как «шакти» (возможность) $)^{17}$ значения. С учетом того, что в философии языка Панини значение языкового выражения зависит также от вивакши (намерения говорящего выразить какое-то содержание), толкование шакти как «возможности значения» равнозначно заявлению о том, что взаимосвязь слов в предложении - не что иное, как потенциальная возможность любого значения, которое может быть связано с любым словом, что слово может выполнить любую роль и может служить совершению любого действия.

Особого разговора заслуживают созданный Панини метаязык и его эффективное применение для сжатия грамматики языка. Великий грамматист трансформировал алфавит, дабы тот удовлетворял целям его металингвистического анализа, а также создал небывалую в истории языкознания технику - специальные технические термины-аббревиатуры для обозначения определенных фонем (пратьяхары). Совсем недавно немецкий лингвист В. Петерсен ${ }^{18}$ предприняла попытку доказать, что количество символов, примененных Панини, является минимально возможным. Следуя примеру Панини, Петерсен создала сходную и столь же эффективную металингвистическую технику представления фонем немецкого языка.

${ }^{17}$ Подробнее см.: Ogawa $H$. On Bhartrhari's notion of Power (śakti) // Bhartrhhari Language: Thought and Reality. Proceedings of the International Seminar of Bhartrhari / Ed. by M. Chaturvedi. Delhi: Motilal Benarsidass, 2009.

${ }^{18}$ Подробнее см.: Petersen W. On the generalizability of Pānini’s Pratyāhāra-Technique to other languages // Proceedings of the $4^{\text {th }}$ Sanskrit Computational Linguistics Symposium / Ed. by G.N. Jha. New Delhi: LNCS, Springer Verlag. 2010. P. 21-38. 
Культура и искусство 2(14) • 2013

Паниниевской модели грамматики придерживались большинство индийских грамматистов ${ }^{19}$ вплоть до XIX в., пока западные грамматисты не попытались написать свои грамматики санскрита; не сумев достичь краткости Панини, равно как и привнести что-либо в метаязык, они обвинили Панини в том, что он написал «варварскую» грамматику.

Проблема метаязыка уже не собственно лингвистическая, но философская; ее постановка трансформирует теорию Панини в лингво-философскую, т. е. имеющую дуальный характер. Характеризуя свой метаязык, Панини указывал, что санскритское слово в его грамматике выступает как фонологическая форма, т. е. совокупность фонем. Например, слово agni (санскр. огонь) в паниниевской грамматике представлено как последовательность звуков «a», «g», «n», «i» (а не «огонь»). Этот тезис Панини оказал огромное влияние на философа Бхартрихари, который отмечал, что слово обладает двоякой функцией: означаемого и означающего (что позднее западный мир узнал от $\Phi$. де Соссюра). Бхартрихари разработал собственную теорию - шабда-брахма-вада (учение о слове как подлинной реальности), сделав универсальным принцип: любое слово выражает прежде всего свою собственную форму; слушающий участник речевого акта изначально опирается на форму слова, значение же, в свою очередь, тоже содержится в форме слова.

Идеи Бхартрихари привели к тому, что в сочинениях по грамматике в объяснения лингвистических феноменов и речевого акта были привнесены философские рассуждения о когнитивных аспектах языка, о соотношении слова и его значения. Последователи школы Панини вербальное восприятие считали отличным от чувственного и рассудочного в том смысле, что для него необходимо априорное знание слова. Бхартрихари же пошел дальше, сказав, что слово лежит в основе всякого восприятия, будь оно вербальное, чувственное или логическое ${ }^{20}$, а действительность - речевой акт, в котором участвует говорящий на определенном языке. Грамматика представляет читателю картину действительности, которая помогает ему постичь эту действительность. Грамматика реальна, потому что она существует, а не в силу той картины, которую представляет. Бхартрихари сравнил язык с картиной и убедительно доказал, что сколь картина реальна как таковая, столь она и нереальна в том смысле, что изображенное на ней нельзя

\footnotetext{
${ }^{19}$ Можно назвать, по крайней мере, с десяток имен его авторитетных последователей.

${ }^{20}$ Подробнее дано: Kulkarni M., Dangarikar C. Word in Cognition [Роль слова в познании] (в печати).
}

связывать с теми физическими действиями, которые объект вполне мог бы осуществить.

Другим философским вопросом, обсуждавшимся грамматистами и философами, был вопрос о взаимосвязи грамматики и языка (конкретно о том, является ли язык предпосылкой возникновения грамматики, или наоборот). Катьяяна поднял этот вопрос еще в 300 г. до н. э. и ответил на него в том смысле, что словоупотребление предшествует грамматике и определяет ее, а затем речевые акты членов языкового сообщества начинают зависеть от обоих: от общепонятности речи и грамматики определенного языка.

Еще более фундаментальным вопросом из числа попавших в поле зрения индийских философов языка было соотношение слова и смысла. В «Йогасутрах» Патанджали (150 г. до н. э.) четко сказано, что области слова и значения, а также их познание различны, но в нашем мире их обычно как бы накладывают друг на друга. Йоги, практикующие концентрацию на указанных трех объектах (слове, значении и знании слова) как на отдельных сущностях, якобы приобретают сверхъестественную способность знать все языки ${ }^{21}$. Бхартрихари утверждал, что существует три типа соотношения слова и значения, обозначенные им как потенция, причинность и наложение (Capacity, Causal and Superimposition) ${ }^{22}$.

Сегодня в Индии в области компьютерной лингвистики для разработки лексических ресурсов широко применяют теорию Бхартрихари, а именно ее раздел о потенциальности значения в слове. Санскритский Wordnet является примером такого peсурса, т. е. онлайнового универсального тезауруса санскрита, разрабатываемого Индийским институтом технологий в Бомбее ${ }^{23}$. Не только санскритский тезаурус, но и вся деятельность по созданию в Индии своей сети под названием Indo-Wordnet базируется на данном принципе и других принципах, сформулированных в санскритских лингвофилософских текстах философами (Бхартрихари и др.). Таким образом, мы видим, что философия языка в Индии всегда вдохновлялась научными достижениями школы Панини, а сегодня философия языка содействует разработке технологического инструментария машинного перевода.

Продолжатель лингво-философской традиции Катьяяна рассматривал важный вопрос, связанный с самой целью существования грамматики. Его исследование имеет значение не только для

${ }^{21}$ Подробнее см.: Kulkarni M. OmniLinguality [«Всеязычие»] (в печати).

${ }^{22}$ Подробнее см.: Ogawa H. Bhartrhhari on three types of Linguistic Unit-Meaning relations [«Бхартрихари о трех типах соотношения лингвистических единиц и смысла»] (в печати). ${ }^{23}$ www.cfilt.iitb.ac.in 
языкознания, но и для науки в целом. Ученый усматривал назначение грамматики в дхарма-нияме - ограничении ради добродетели (restriction for the Merit) ${ }^{24}$. Он открыто признавал, что и так называемые грамматические, и так называемые неграмматические единицы языка идентичны в аспекте коммуникации, этого основополагающего назначения языка, и действительно доносят смысл до слушателя. Однако обязанность грамматики состоит в том, чтобы сообщить носителю языка, какое высказывание (грамматическое или неграмматическое) поможет ему стяжать заслуги. Интерпретация Катьяяны - уникальное явление во всемирной истории языкознания и философии языка. Указанный довод можно развить и применить к науке в целом, равно как и утверждать, что главная цель науки - ограничение ради добродетели.

Думаю, Катьяяна понял глубинную природу науки, которая есть гармония, а не разрушение, и современный мир должен аплодировать ему за это ге- ниальное прозрение, за его научную деятельность, с одной стороны, и философию - с другой. Если бы мы следовали заветам Катьяяны, проблемы современного мира (в плане гонки вооружений и т. п.) были бы разрешены более чем наполовину 25 .

Многочисленные приведенные здесь примеры постоянного взаимодействия философии языка и языкознания в Индии позволяют вполне определенно констатировать огромный интерес научной мысли к языку как в аспекте языкознания, так и в аспекте философии языка. Создается впечатление, что индийские мыслители никогда не рассматривали эти две дисциплины порознь, как нечто совершенно отдельное друг от друга. Их скорее полагали двумя сторонами одной и той же монеты, когда одна - в помощь другой, а другая - во благо первой дополняют друг друга. Хотелось бы предложить это в качестве идеального способа взаимодействия в деле решения всех остальных проблем двух областей знания: науки и философии.

\section{Список литературы:}

1. Bharati A., Chaitanya V., Sangal R.A Natural Language Processing: Pāṇinian perspective (Indian Institute of Technology, Kanpur). New Delhi: Prentice-Hall of India. 1995.

2. Belvalkar S. K. Systems of Sanskrit Grammar. Reprint, Delhi: Bharatiya Vidya. Prakashan, 1976.

3. Böhtlingk O. Pāninini’s Grammatik. Hildesheim: Georg Olms Verlag, 1887. Reprint, N.Y., 1971.

4. Cardona G. Pāninini: a survey of research. Delhi: Motilal Benarsidass, 1976.

5. $\quad$ Cardona G. Recent Researches in Pānininian studies. Delhi: Motilal Benarsidass,1998.

6. Coward H. and Kunjunni Raja K. Part one : Introduction to the Philosophy of the Grammarians // Encyclopedia of Indian Philosophy. Vol.5. Delhi: Motilal Banarsidass and Princeton University Press, 1990. P. 3-97.

7. Iyer S., K.A. Bhartṛhari. A Study of Vākyapadīya in the Light of Ancient Commentaries. Poona: Deccan College Postgraduate Research Institute, 1969, reprint 1997.

8. Kulkarni M. Contribution of Kātyāyana to Pāṇinian grammar. Pāninini to Patañjali: a grammatical march. New Delhi: D. K. Printworld, 2004.

9. Kulkarni M. OmniLinguality (Forthcoming).

10. Kulkarni M., Chaitali D. Word in Cognition. (Forthcoming)

11. Ogawa H. On Bharț̣hari's notion of Power (śakti) // Bhartṛhari Language: Thought and Reality. Proceedings of the International Seminar of Bhartrihari / Ed. by M. Chaturvedi. Delhi: Motilal Benarsidass, 2009.

12. Ogawa H. Bhartṛhari on three types of Linguistic Unit-Meaning relations (Forthcoming).

13. Petersen W. On the generalizability of Pānini's Pratyāhāra-Technique to other languages // Proceedings of the $4^{\text {th }}$ Sanskrit Computational Linguistics Symposium / Ed. by G.N. Jha. New Delhi: LNCS, Springer Verlag. 2010. P. 21-38.

\footnotetext{
24 Этот тезис совпадает с одним из важнейших принципов западной постнеклассической науки - принципом гуманитаризации знания. - Примеч. ред.
}

${ }^{25}$ Подробнее см.: Kulkarni M. Contribution of Kātyāyana to Pāninian grammar // Pānini to Patañjali : a grammatical march / Ed. by D. K. Printworld. New Delhi, 2004. 